NBER WORKING PAPER SERIES

\title{
PRIVATE PROFITS AND PUBLIC HEALTH: DOES ADVERTISING SMOKING CESSATION PRODUCTS ENCOURAGE SMOKERS TO QUIT?
}

\author{
Rosemary Avery \\ Donald Kenkel \\ Dean R. Lillard \\ Alan Mathios \\ Working Paper 11938 \\ http://www.nber.org/papers/w11938
NATIONAL BUREAU OF ECONOMIC RESEARCH
1050 Massachusetts Avenue
Cambridge, MA 02138
January 2006

This research was supported by Award \# R01 CA094020-01 from the National Cancer Institute to Cornell University, an award from the Substance Abuse Policy Research Program of the Robert Wood Johnson Foundation to the National Bureau of Economic Research, and an unrestricted educational grant to Cornell University from The Merck Company Foundation, the philanthropic arm of Merck \& Co. Inc. Eamon Molloy and Vandana Plassmann provided valuable research assistance. Participants at seminars at the Medical University of South Carolina, the 2005 International Health Economics Association Conference, the University of Kentucky, and the 2005 Robert Wood Johnson Foundation Substance Abuse Policy Research Program Annual Grantee Meeting provided helpful comments. The views expressed herein are those of the author(s) and do not necessarily reflect the views of the National Bureau of Economic Research.

(C2006 by Rosemary Avery, Donald Kenkel, Dean R. Lillard and Alan Mathios. All rights reserved. Short sections of text, not to exceed two paragraphs, may be quoted without explicit permission provided that full credit, including $(\odot)$ notice, is given to the source. 
Private Profits and Public Health: Does Advertising Smoking Cessation Products Encourage

Smokers to Quit?

Rosemary Avery, Donald Kenkel, Dean R. Lillard and Alan Mathios

NBER Working Paper No. 11938

January 2006

JEL No. I1, L1

\begin{abstract}
To shed new light on the role private profit incentives play in promoting public health, in this paper we conduct an empirical study of the impact of pharmaceutical industry advertising on smoking cessation decisions. We link survey data on individual smokers with an archive of magazine advertisements. The rich survey data allow us to measure smokers' exposure to smoking cessation advertisements based on their magazine-reading habits. Because we observe the same information about the consumers that the advertisers observe, we can control for the potential endogeneity of advertising due to firms' targeting decisions. We find that when smokers are exposed to more advertising, they are more likely to attempt to quit and are more likely to have successfully quit. While some of the increased quitting behavior involves purchases of smoking cessation products, our results indicate that advertisements for smoking cessation products also increase the probability of quitting without the use of any product. Thus, the public health returns to smoking cessation product advertisements exceed the private returns to the manufacturers. Because advertising of a wide range of consumer products may have important and under-studied spillover effects on various non-market behaviors, our results have broad implications for the economics of advertising.

Rosemary Avery

Department of Policy Analysis

and Management

Cornell University

Ithaca, NY 14850

rja7@cornell.edu

Donald Kenkel

Department of Policy Analysis

and Management

Cornell University

Ithaca, NY 14850

and NBER

dsk10@cornell.edu

Dean R Lillard

Department of Policy Analysis

and Management

Cornell University

Ithaca, NY 14850

drl3@cornell.edu

Alan Mathios

Department of Policy Analysis

and Management

Cornell University

Ithaca, NY 14850

adm5@cornell.edu
\end{abstract}




\section{Introduction}

An on-going public health initiative, Healthy People 2010, aims to cut the prevalence of smoking among U.S. adults almost in half, to 12 percent by 2010 (USDHSS 2000). Although preventing youth from starting to smoke has probably attracted more attention, experts point out that the Healthy People 2010 objective can not be met unless the rate of smoking cessation increases (Mendez and Warner 2000, 2004). The Centers for Disease Control and Prevention “Best Practices” call for State tobacco control programs to spend about $\$ 1$ billion annually for smoking cessation counseling and services (CDC 1999); but on average, States’ investments in tobacco control are substantially below the Best Practices guidelines (CDC 2001a). At the federal level, the U.S. Interagency Committee on Smoking and Health has endorsed a new National Action Plan for Tobacco Cessation that includes \$3.2 billion per year for a national quitline and \$1 billion per year for a national media campaign (Fiore et al. 2004).

Although many smokers quit 'cold turkey’ without assistance, smokers are more likely to successfully quit if they use a pharmaceutical smoking cessation product such as a nicotine replacement therapy (Fiore et al. 2000). The cessation product industry’s estimated retail sales are nearly $\$ 1$ billion annually, and in recent years the industry has spent between $\$ 100$ to $\$ 200$ million annually advertising these products (Marketdata Enterprises 2000; MarketResearch 2005; Competitive Media Reports, various years). The potential public health benefits of this advertising have not been overlooked. For example, in 1996 the American Cancer Society’s Great American Smoke Out (GASO) included an advertising campaign that was jointly sponsored with a manufacturer of a cessation product. Burton et al. (1997) estimate that paid advertisements from the 1996 GASO campaign reached 122 million adults. To shed new light 
on the role private profit incentives play in promoting public health, in this paper we conduct an empirical study of the impact of pharmaceutical industry advertising on smoking cessation decisions.

Advertising's role in the economy is controversial, and advertising in health-related markets is especially so. Currently, the U.S. and New Zealand are the only countries that allow direct-to-consumer (DTC) advertising of pharmaceutical products. The U.S. pharmaceutical industry’s expenditures on DTC advertising increased from $\$ 300$ million in 1993 to $\$ 3.75$ billion in 2002 (Rosenthal et al. 2002). Empirical studies provide a growing body of evidence on the impact of DTC advertising on consumer demand for pharmaceutical products ${ }^{1}$. Recently, however, manufacturers have been forced to withdraw heavily-advertised products for safety reasons, prompting new concerns about DTC advertising. In other health-related markets, producer advertising has been shown to be an important source of health information that leads to changes in dietary fiber and fat consumption (Ippolito and Mathios 1990, 1995).

To contribute a case study to the academic and policy debates about advertising, this paper develops estimates of the key impacts of magazine advertisements of smoking cessation products. As discussed in more detail in section II below, private incentives to advertise these products partially align with the public health objective to increase smoking cessation. But to the extent product advertising spills over and encourages cold turkey cessation, the

${ }^{1}$ Bradford and Kleit (2006) provides a review of this research. Notable examples include Berndt et al. (1995), Iizuka and Jin (2005a. 2005b), Ling, Berndt and Kyle (2002), Calfee, Winson and Stempski (2002), Rosenthal et al. (2003), Tauras, Chaploupka and Emery (2005), and Wosinska (2003, 2005). 
advertisements create positive externalities and some of the social returns to advertising are not captured as private profits.

Our data and econometric approach are discussed in sections III and IV. Identifying the causal impact of advertising is a difficult empirical challenge. The relationship between advertising and consumption is literally a textbook example of simultaneous equations (Berndt 1991): Are consumers responding to the advertising, or are advertisers responding to the consuming? Studies that rely on instrumental variables to identify the causal impact of pharmaceutical advertisements face the almost inevitable questions about the validity and strength of the IVs. Our alternative approach is to instead exploit rich data that provide what we argue is a strong identification strategy. We link survey data on individual smokers with an archive of magazine advertisements. The rich survey data allow us to measure the smokers' exposure to smoking cessation advertisements based on their magazine-reading habits. Because we observe the same information about the consumers that the advertisers observe, we can control for the potential endogeneity of advertising due to firms' targeting decisions. In addition, we control for the general category of magazines consumers read: general interest, women's, and so on. With these controls, our identification is based on within-category variation in exposure to advertisements, for example because one smoker reads Time while another reads Newsweek.

Our results are presented in section $\mathrm{V}$. We find that when smokers are exposed to more advertising, they are more likely to attempt to quit and are more likely to have successfully quit. While some of the increased quitting behavior involves purchases of smoking cessation products, our results indicate that advertisements for smoking cessation products also increase the probability of quitting without the use of any product. Thus, the public health returns to smoking 
cessation product advertisements exceed the private returns to the manufacturers. Section VI closes the paper with discussion of the broader implications of our results.

\section{Background and Framework for Analysis}

\section{Profit-Maximizing Advertising of Smoking Cessation Products}

Smokers’ desires to quit create a healthy demand for smoking cessation products. In surveys, most smokers claim that they want to quit, and nearly half of current smokers report having stopped smoking for at least one day in the past year in an attempt to quit (CDC 2005). When they attempt to quit, at least two-thirds of smokers use a method like 'cold turkey' that does not involve a product purchase. However, in recent years about 20 percent of smokers who attempt to quit report using a pharmaceutical smoking cessation product (Plassman et al. 2005).

To set the stage for the role of advertising, first consider a simple utility-maximizing model of consumer demand for smoking cessation products. Assume that smoking cessation, $q$, is produced in the household through some combination of smoking cessation products, $s$, which are purchased in the market, and non-market inputs of time and effort: $q=q(\mathrm{~s},$.$) . The demand$ for smoking cessation products is thus derived from the demand for smoking cessation. The demand for smoking cessation, in turn, is derived from the demand for health. The private value of smoking cessation $v$ could be formally defined as the difference in lifetime utility from quitting and the lifetime utility from continuing to smoke (Becker and Murphy 1988; Suranovic, Goldfarb, and Leonard 1999; Jones 1999). To find the utility-maximizing choice of smoking cessation products $\left(s^{*}\right)$, the consumer sets the marginal benefits equal to the market price $\left(\mathrm{P}_{\mathrm{S}}\right)$ :

(1) $\quad v \cdot q_{S}=\mathrm{P}_{\mathrm{S}}$ 
where $q_{S}$ is the consumer's perception of the marginal product of smoking cessation products in producing a successful quit.

Advertising can provide consumers information about the health benefits of quitting $(v)$, and it can provide information about the usefulness of the products as an aid to quitting $\left(q_{s}\right)$. (Price advertising does not seem common in this market.) This implies a market demand function for smoking cessation products as a function of product price and advertising messages (M): $\mathrm{S}=\mathrm{S}\left(\mathrm{P}_{\mathrm{S}}, \mathrm{M}\right)$. Our approach focuses on informative advertising for a smoking cessation product as a search good. Although an advertisement can provide information about the average effectiveness of the product in helping smokers quit, there appears to be substantial individual heterogeneity so that a product may or may not be that helpful for a specific smoker. In this way a smoking cessation product also has the characteristics of an experience good. However, unlike other experience goods, once the smoker finds the product that works for him, there will not be repeat purchases. While we use a simple static model, we recognize that in reality smoking cessation is a process that often involves multiple attempts (Prochaska and DiClemente 1983, DiClemente et al 1991).

We use a standard model of the economics of monopoly advertising to examine the profit incentives to advertise smoking cessation products. ${ }^{2}$ Let the profits of a monopolist manufacturer of a smoking cessation product be given by:

(2) Profits $=\mathrm{P}_{\mathrm{S}} \mathrm{S}\left(\mathrm{P}_{\mathrm{S}}, \mathrm{M}\right)-\mathrm{C}\left(\mathrm{)}-\mathrm{M} \mathrm{P}_{\mathrm{M}}\right.$

${ }^{2}$ Bagwell (2005) provides an excellent review of the economics of advertising. Although Nicorette gum's monopoly ended in 1992 with the introduction of the nicotine patch, as Bagwell (2005, p. 54) argues, the monopoly case "represents a simple setting within which to begin the formal analysis of advertising." The model traces back to Dorfman and Steiner (1954) and Schmalensee (1972). 
where in addition to terms defined above, C ( ) is the firm's cost function for producing smoking cessation products and $\mathrm{P}_{\mathrm{M}}$ is the price it pays for advertising messages (as a price taker in the advertising market).

The first order condition for the profit-maximizing level $\mathrm{M}^{*}$ of advertising messages is:

$$
\left(\mathrm{P}_{\mathrm{S}}-\mathrm{MC}\right)[\partial \mathrm{S} / \partial \mathrm{M}]=\mathrm{P}_{\mathrm{M}}
$$

In words, equation (3) simply states that the manufacturer equates the marginal impact of an advertising message on its profits $\left(\mathrm{P}_{\mathrm{C}}-\mathrm{MC}\right)$ to the price of an advertising message. If there were competing firms in the market, the relevant version of equation (3) would include additional terms that capture the impact of the conjectured reactions of its competitors to the firm’s own advertising.

\section{Advertising of Smoking Cessation Products and Public Health}

While the manufacturer is concerned with sales of its product, the public health objective concerns successful smoking cessation. A simple analysis suggests three reasons that, compared to the socially desirable level, private smoking cessation product manufacturers may fail to advertise enough due to: (i) the public health externalities from the advertising; (ii) the public health externalities from smoking cessation; and (iii) the monopoly distortion in the market.

Consider an aggregate or societal production function that shows the annual number of smokers who quit $(Q)$ as a function of the aggregate use of smoking cessation products $(S)$ and the use of 'cold turkey' or non-purchased methods (T) of smoking cessation: $Q=Q(S, T)$. Empirical studies suggest that DTC advertising of one pharmaceutical product can spill over and increase demand for related products (Ling, Berndt and Kyle 2002, Rosenthal et al. 2003, Wosinska 2003, 2005 and Iizuka and Jin 2005a). Analogously, we assume that advertising 
messages for smoking cessation products not only increase product sales $(\partial S / \partial M>0)$, but may also spill over and affect smokers' attempts to quit without purchasing any product $(\partial T / \partial M>0)$. If $V$ is the social value or societal willingness to pay per successful smoking cessation, the net social benefits of advertising smoking cessation products are:

(4) Net social benefits $=V \bullet \mathrm{Q}\left(\mathrm{S}\left(\mathrm{P}_{\mathrm{S}}, \mathrm{M}\right), \mathrm{T}(., \mathrm{M})\right)-\mathrm{P}_{\mathrm{M}} \mathrm{M}$

The socially optimal amount of advertising $M^{* *}$ is where the social marginal benefits equal the marginal cost of advertising:

(5) $\left.\quad V \cdot \mathrm{Q}_{\mathrm{S}}(\partial \mathrm{S} / \partial \mathrm{M})+\mathrm{V} \mathrm{Q}_{\mathrm{T}}(\partial \mathrm{T} / \partial \mathrm{M})\right]=\mathrm{P}_{\mathrm{M}}$

Comparing the left hand sides of equations (3) and (5) reveals the extent to which private profit incentives to advertise are aligned with public health goals. The first point to note is that in the static framework used, in equation (3) the manufacturer's profits do not depend on whether the product is actually effective $\left(Q_{S}>0\right)^{3}$. This point is moot for the case of modern smoking cessation products, because there is strong evidence of effectiveness. Based on a meta-analysis of evidence from clinical trials, the current Public Health Service’s Clinical Practice Guidelines concludes that: "Numerous effective pharmacotherapies for smoking cessation now exist....that reliably increase long-term abstinence rates,” and identifies buproprion, nicotine gum, nicotine inhaler, nicotine nasal spray, and the nicotine patch as first-line pharmacotherapies (Fiore et al. 2000). The results of the meta-analysis suggest that compared to the control groups (cold turkey quitting), product use approximately doubles the probability of successful smoking cessation. Note that 'cold turkey' quitting is sometimes successful, however, so $Q_{T}$ is also positive.

${ }^{3}$ Clearly, this would not hold in a dynamic setting where future potential consumers of the product could learn about its ineffectiveness. 
The spillover effects of product advertising on cold turkey quitting are given by the second term on the left hand side of equation (5). The sign and magnitude of the impact of private advertising on cold turkey quitting, $\partial T / \partial M$, is an empirical question. Given that product advertising may often serve to inform or remind smokers of the private value of quitting, it is reasonable to expect that $\partial T / \partial M$ is also positive, creating positive public health externalities from private advertising.

In addition to the advertising externalities, comparing the first terms in equations (3) and (5) reveals the possible public health externalities from smoking cessation and the monopoly distortion in the market. These suggest additional reasons that the profit-maximizing level of advertising $M^{*}$ will fail to reach the socially desirable level $M^{* *}$. Because utility maximization implies that the consumer sets the marginal benefits of product use equal to its market price, from equation (1) we can substitute $v \bullet q_{S}$ for $P_{S}$ in the first term in equation (3). The comparison of the first terms then hinges on how $\left(v \bullet q_{S}-M C\right)$ compares to $V \bullet Q_{S}$. If consumer perceptions of the effectiveness of the products are on average correct, then $q_{S}=Q_{S}$. Public health externalities from smoking cessation - including the reduction of secondhand smoke and insurance externalities - may mean that the social value of smoking cessation is greater than the private value: $V>v .{ }^{4}$ The monopoly distortion in the product market also means that increasing

\footnotetext{
${ }^{4}$ Some estimates suggest that current cigarette taxes are sufficiently high so that the net negative externality of smoking is small or zero (Manning et al 1991; Viscusi 1995). More recently, Sloan et al. (2004) estimate that the external cost of smoking is $\$ 2.20$ per pack, substantially higher than the average excise tax on cigarettes in the U.S. The remaining uninternalized external costs of smoking imply that the social value of quitting, $V$, is greater than the private value of quitting, $v$. By the same token, if by lowering the perceived addiction costs, smoking cessation product advertisements have the unintended consequence of increasing smoking initiation, the advertisements could generate negative externalities. Because we do not have data on smoking initiation, our empirical analysis focuses on smoking cessation.
} 
product use is socially valuable at the margin. Although the smoking cessation product market is no longer a pure monopoly, this type of distortion is probably still relevant because patents and the FDA approval process limit the extent of market competition. Under these assumptions, $\left(V \cdot Q_{S}\right)>\left(v \cdot q_{S}\right)-M C$

Our analysis thus suggests a number of reasons to expect that the marginal social benefits of advertising smoking cessation products are larger than the marginal impact on the firm's profits. Assuming diminishing marginal effectiveness of advertising messages implies that the socially optimal level of advertising $M^{* *}$ must therefore exceed the profit-maximizing level $M^{*}$. This conclusion emerges from a simple model that highlights some of the main tradeoffs in the welfare economics of advertising smoking cessation products. In our empirical analysis we estimate whether and how advertising affects several types of smoking cessation behavior. Our estimates shed light on the private and public returns from smoking cessation product advertisements. In terms of private profits, we directly estimate whether and how much advertisements change the probability that a smoker attempts to quit using a smoking cessation product. This estimate corresponds to the term $\partial S / \partial M$ in equation (3). In terms of public health, we also estimate whether and how much advertising affects the probability that a smoker successfully quits - both overall and with or without the use of a product. These estimates of the total impact of advertising correspond to the terms $Q_{S} \bullet \partial S / \partial M$ and $Q_{T} \bullet \partial T / \partial M$ in equation (5).

\section{The Data and the Variables of Analysis}

\section{Data}

Our individual-level data comes from a marketing survey, the Simmons National Consumer Survey (NCS). The NCS provides detailed information on consumer behavior and 
magazine-reading and television-viewing habits (NCS 2005). The Data Appendix provides additional information about the NCS. We pool data from the Fall 1995, Spring 1996, Spring 1997, Fall 1997, Spring 1998, Fall 1998, and Fall 1999 cross-sections of the NCS. Because we are studying smoking cessation, we restrict our sample to the 36,097 current or former smokers who report having been a smoker within the past year.

We draw our advertising data from the Smoking Cessation Advertisements (SCADS) archive that we compiled. The SCADS archive is a collection of all print advertisements for smoking cessation products, tobacco products, and smoking-related public service announcements that appeared between January 1985 and May 2002 in 26 consumer magazines. The magazine set includes: Better Homes \& Gardens, Black Enterprise, Business Week, Cosmopolitan, Ebony, Essence, Family Circle, Glamour, Good Housekeeping, Jet, McCall's, Modern Maturity, Money, National Geographic, Newsweek, People, Playboy, Readers Digest, Rolling Stone, Seventeen, Sports Illustrated, Time, TV Guide, U.S. News \&World Report, Vogue, and Women's Day. We selected these magazines to represent magazines most frequently read by individuals with particular demographic characteristics. Using magazine circulation and readership data from three independent sources, we estimate that the 26 magazines in SCADS account for between 30.0 and 57.5 percent of magazine circulation or readership in the US. (The Data Appendix provides additional discussion of the choice of magazines and the sources of these estimates.)

Although the SCADS magazines are a substantial portion of the market, the sample of advertisements in SCADS is not a strictly random sample of all magazine advertisements. To establish how well advertising in SCADS magazines tracks all magazine advertising, we 
compare the number of advertisements of smoking cessation products in SCADS to data from

Competitive Media Reports on magazine advertising expenditures for the same products. Figure

Figure 1

SCADS advertisements versus CMR magazine advertising expenditures

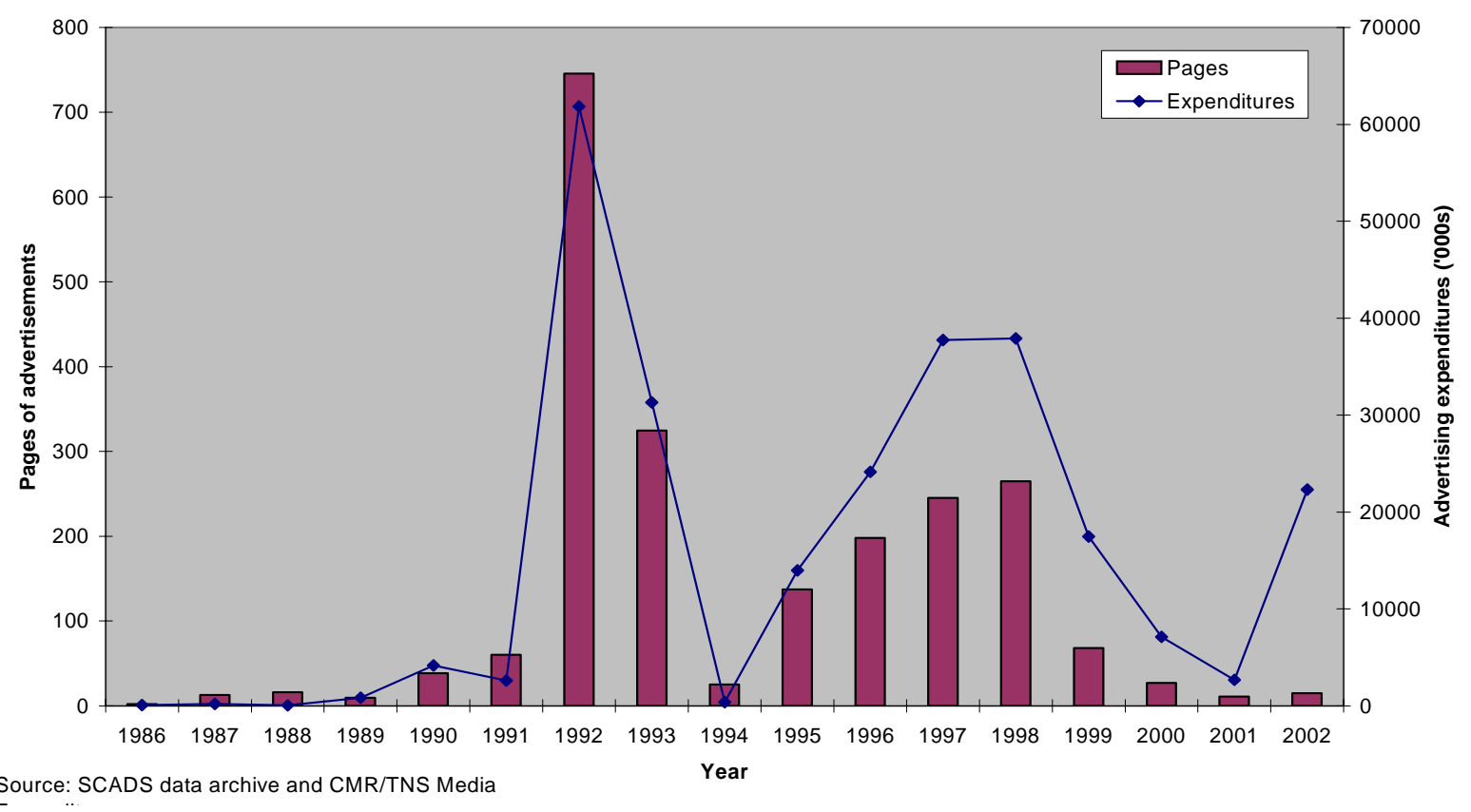

1 plots the pages of advertisements that appeared in the SCADS magazines in each year and total magazine advertising expenditures in the same years. Figure 1 shows that the advertising in SCADS closely tracks total advertising expenditures. ${ }^{5}$ The only deviation between the SCADS advertisements and the annual advertising expenditures is in 2002. That difference occurs because currently the SCADS archive ends in May, before the October 2002 launch and subsequent advertising of the Commit nicotine lozenge.

${ }^{5} \mathrm{~A}$ simple regression of monthly advertising expenditures on the number of SCADS advertisements in that month confirms that the variation in the SCADS data explains most of the variation in advertising expenditures (R-squared $=0.79)$. 
Table 1 presents the definitions and descriptive statistics for the main variables of interest created from the NCS and the SCADS data. Appendix Table A1 presents summary statistics for the other variables we include in our models. We now turn to a more detailed discussion of the key measures of smoking cessation behavior, advertising exposure, and other control variables used in our analysis.

\section{Measures of Smoking Cessation Behavior}

We created a series of measures of smoking cessation behavior using responses to several questions posed to all NCS respondents. We use responses to the question, "Did you attempt to quit smoking in the past 12 months?” to code our measure of a quit attempt. Forty-three percent of our sample of smokers attempted to quit in the past 12 months; this is comparable to estimates from the National Health Interview Survey and other national health surveys. We combine the response to the question about quit attempts with answers to the question, "Do you currently smoke?" to identify respondents who "successfully" quit. These individuals are smokers who tried to quit smoking the past year and do not currently smoke. Measured this way, 9.4 percent of our sample successfully quit. This quit rate is higher than other estimates that suggest that less than 5 percent of current smokers successfully quit each year. This difference is at least partly because the time frame of the NCS does not allow us to measure long-term abstinence from smoking. Although for convenience we use the term "successful quitting" in the remainder of this paper, this caveat should be kept in mind. Another caveat is that the self-reported quitting behavior may not always be accurate. However, a meta-analysis of studies that compared selfreported smoking with biochemical markers of smoking shows that most people accurately 
report their smoking status (Patrick et al 1994), which provides indirect support for the accuracy of self-reported quitting behavior.

The NCS also asked all respondents who attempted to quit smoking about the methods they used in the attempt. We combined these responses with our measures of attempted and successful quits to create additional measures of smoking cessation: a quit attempt with the use of a smoking cessation product; a quit attempt without the use of a smoking cessation product; a successful quit with the use of a smoking cessation product; and a successful quit without a smoking cessation product. When we use the various measures of smoking cessation behavior as dependent variables in our econometric models, except for the probability of a quit attempt, the probability being estimated is the joint probability of each previous decision. For example, when we estimate the probability of a successful quit attempt using a smoking cessation product, we are estimating a model of the joint probability that a smoker attempts to quit, the probability he uses a smoking cessation product, and the probability that he succeeds.

\section{Measure of Individual Exposure to Advertising}

To construct measures of the advertising to which each NCS respondent was exposed we merge all of the SCADS advertising data to each person in the NCS sample. In the NCS, each respondent is shown copies of the covers of over 100 consumer magazines. He then reports how many of the last four issues of each magazine that he read. The variable $\operatorname{Read}_{\mathrm{im}}$ is the fraction of issues of magazine m read by person i. For each SCADS magazine that an NCS respondent reported having read, we multiply the fraction of the last four issues he read times the number of advertisements that appeared in that magazine over the previous 12 months. Note that, in doing so, we assume that an individual's reading habits over the past four issues reflects his reading 
habits over the past year. We then sum over all magazines in the SCADS sample. The result is our estimate of advertising to which a person was potentially exposed by reading the SCADS magazines. For example, the exposure to smoking cessation product advertising of respondent $\mathrm{i}$ $\left(\mathrm{AdExp}_{i}\right)$ is given by:

(6) $\quad \operatorname{AdExp}_{\mathrm{i}}=\sum_{m=1}^{26} A d s_{i m} * \operatorname{Re} a d_{i m}$

where subscript m refers to each of the 26 magazines in the SCADS sample. Our measurement approach assumes that two people who read the same number of issues of the same magazines were exposed to the same number of advertisements. This is imperfect because we do not know if both people actually saw the advertisements, but it represents a vast improvement over previous research. Previous studies use market-level data on advertising, which requires the implicit assumption that all individuals in a given market are exposed to the same advertising.

We construct exposure measures for smoking cessation products, cigarettes, other tobacco products, and smoking-related public service announcements (PSA). Based on our measures, the average current or former smoker in our sample was exposed to 13.5 advertisements for smoking cessation products over a 12 month period. By contrast, the average current or former smoker was exposed to more than ten times as many advertisements for cigarettes in the same magazines -about 144.9 advertisements over a 12 month period, but was exposed to very few (less than one) anti-smoking PSAs.

To get a first glimpse of the relationship between cessation behavior and exposure to advertising of smoking cessation products, Table 2 shows the fraction of past-year smokers who attempt to quit and the fraction who successfully quit across different quartiles of the distribution 
of exposure to advertisements for smoking cessation products. Table 2 shows a clear relationship between the number of smoking cessation product advertisements a past-year smoker potentially saw and the propensity to attempt to quit. While 39.6 percent of smokers in the first quartile of the exposure distribution attempted to quit, 46.4 percent attempted to quit if they were in the highest quartile of the exposure distribution. The fraction of past-year smokers who attempt to quit steadily increases as they are exposed to more smoking cessation product advertising. However, when one plots the fraction of past-year smokers who successfully quit against exposure to smoking cessation product advertising no clear pattern emerges. Roughly the same fraction of past-year smokers in the first and fourth quartiles succeeded in their quit attempt (9.5 and 9.8 percent respectively).

\section{Other Control Variables}

We also include in our models standard socio-economic control variables (age, sex, race, education, marital status, family size, presence of children in the household, employment status, family income) as well as controls for overall magazine-reading habits, television-viewing habits, and radio-listening habits. Over the previous 12 months, the average person in our sample read 144 issues of one or more of the magazines consistently included in the NCS. Note that only four percent of respondents reported that they read no magazines. The average current or former smoker in our sample watched 23 hours of television per week and listened to the radio about 4 hours per week. Sixteen percent of the sample watched no television and 26 percent did not listen to the radio in an average week. 


\section{Econometric model and identification}

As defined above, we use various discrete measures of smoking cessation behavior in the past year as our key dependent variables. We adopt the usual approach by assuming that the discrete outcomes we observe are related to underlying latent variables describing the net benefits of the smoking cessation behaviors ${ }^{6}$. We assume the underlying latent variables are linear functions of exposure to advertising and characteristics of the person and his household. We specify the general relationship as:

(7) $\quad Y_{i}^{*}=\gamma_{0}+\gamma_{1} \operatorname{AdExp}_{\mathrm{i}}+\mathrm{Z} \gamma_{2}+\epsilon_{\mathrm{i}}$ where $A d \operatorname{Exp}_{i}$ refers to exposure to smoking cessation advertising, $Z$ is a vector of other control variables, and $\epsilon_{i t}$ is an error term. We observe the given smoking cessation behavior (denoted by $Y_{i}$ ), only if the continuous latent variable exceeds a critical threshold. Under the standard formulation, $Y_{i}=1$ if $Y_{i}^{*}>0$ and $Y_{i}=0$ otherwise. We estimate equation (7) by maximum likelihood probit.

Our econometric approach uses variation in exposure to advertisements due to magazinereading habits as a natural experiment to identify the causal effect of advertising on smoking cessation. Because the NCS data allow us to include a rich set of control variables in our models, we believe that the identifying variation in advertising exposure is exogenous, i.e., $\operatorname{AdExp}_{i}$ is uncorrelated with the error term $\epsilon_{i}$ in equation (7). In addition to including standard

${ }^{6}$ For example, for the latent variable $\mathrm{y}^{*}$ that describes the net benefits of attempting to quit with a smoking cessation product, equation (1) implies that $\mathrm{y}^{*}=v q_{S}-\mathrm{P}_{\mathrm{S}}$. As discussed above, advertising may change the value a smoker attaches to quitting $(v)$ and how effective he thinks the product will be $q_{s}$. Characteristics such as age and schooling are included in the vector of explanatory variables $\mathrm{Z}$ in equation (7) as additional possible determinants of v. Our data lack measures of $\mathrm{P}_{\mathrm{S}}$, the price of the product. Below we discuss why we expect product price to be uncorrelated with our measure of advertising exposure. 
controls for individual socio-economic characteristics, we take several steps to further strengthen our identification strategy. First, our models include controls for general magazine-reading habits and exposure to other media. In this way, we control for the possibilities, say, that heavy magazine-readers or television-watchers somehow differ in their unobserved propensity to quit smoking. Second, and probably more important, our models include a set of dummies reflecting whether an individual read at least one issue of a SCADS magazine in the following general categories: general interest, women's, young women’s, men’s, and African-American. We also include a set of over 100 dummies reflecting whether an individual read at least one issue of each of the over 100 other magazines not included in SCADS. With these controls, our identification is based on within-category variation in exposure to advertisements in the SCADS magazines, for example because one person reads Time while another reads Newsweek.

The richness of our data allow us to address two potential challenges to relying on this type of natural experiment for identification. First, it would be an invalid source of identification if there are unobserved characteristics that determine people's choices to read Time instead of Newsweek that also determine their smoking cessation decisions. In other consumer contexts, this seems likely. For example, some speciality magazines cater to consumers with specific spending propensities; consumers who read a magazine devoted to firearms are more likely to purchase ammunition, independent of their exposure to ammunition advertisements. In our context, the measure of advertising is unlikely to be correlated with unobservable characteristics in this way because we measure advertising in magazines read by general audiences or by broad sub-groups (women's, men's, etc.). We believe it is implausible that smokers who plan to quit choose to read Time because it contains more advertisements for smoking cessation products. 
Second, our identification strategy would be weaker if we did not observe the individual characteristics the firms might use to target advertisements across magazines. Table 3 reports the results of an auxiliary regression that suggests that firms do in fact use the characteristics of magazines' readers to target advertising. The regression shows that our measure of advertising exposure $\left(\operatorname{AdExp}_{i}\right)$ is statistically and significantly associated with a number of observable characteristics. For example, past-year smokers are exposed to more advertisements if they are older (up to the age of about 60), more educated, female, higher income, and have health insurance. These characteristics are also very plausibly associated with a higher propensity to attempt to quit, even independent of differences in advertising exposure. The patterns in Table 3 are thus consistent with profit-maximizing producers targeting their advertisements to magazines read by many potential quitters, in order to capture a larger market share of those quitters as buyers of their products. So even if the advertisements do not encourage cessation, this reverse causality would yield spurious results in our probit models of the effect of advertising on smoking cessation behaviors.

However, the strength of our data largely eliminates the potential for reverse causality. We are using exactly the same data that producers use for their advertising decisions: The NCS website's promotion materials state that their data are used by every major marketing firm and advertising agency in the U.S. (NCS 2005). Therefore, as econometricians we can observe and control for the same characteristics that firms use to target advertising. Instead of being in the error term $\epsilon_{i}$ in equation (7), we include these characteristics in the $Z$ vector. $^{7}$ Because we

${ }^{7}$ Of course, we do not include literally every possible explanatory variable from the NCS data. Our claim is that our econometric specification approximates the model firms use to target their advertisements. 
control for the same characteristics, we econometrically identify the effect of advertising using differences in exposure for people who are observationally equivalent on the observed characteristics. For example, while all college-educated smokers are exposed to more advertisements, our identification does not use between-educational-group variation and only relies on the within-group variation among past-year smokers with similar levels of education.

Our identification strategy should also minimize any bias stemming from the fact that data limitations force us to omit from our empirical models: product prices; cigarette prices; and measures of tobacco control policies. ${ }^{8}$ Because firms simultaneously choose advertising levels and product prices, in some empirical contexts it would be important to control for the product prices consumers face. Similarly, because firms might adjust their advertising of smoking cessation products in reaction to a state cigarette tax hike or enactment of a new worksite smoking ban, it could be important to control for these variables as well. However, we exploit individual level variation in advertising exposure that arises because individuals read different nationally distributed magazines. In this empirical context, the variation in advertising exposure can be expected to be uncorrelated with state and local variation in product prices, cigarette prices, and tobacco control policies. Product prices could be correlated with our measure of advertising exposure only if firms can price discriminate across consumers. Although firms may be able to price discriminate across consumers by providing coupons, of the advertisements for

\footnotetext{
${ }^{8}$ Although it has many advantages, the NCS data set does not contain prices of smoking cessation products and does not consistently provide information on respondents' geographic location (which could be used to merge market-level price measures and policy variables). The 1999 wave of the NCS contains information on the state of residence of all respondents. For the 1995-1998 waves, the NCS contains information on the city of residence for respondents living in the largest markets. Using this information, it is possible to identify state of residence for about half of these samples.
} 
smoking cessation products in the SCADS archive from 1994 - 1999, only 8 percent (38 of 451 advertisements) contained references to coupons. ${ }^{9}$ This suggest our empirical strategy will mainly identify an advertising effect, not a coupon effect.

As a final note, we compare our identification strategy to approaches used in previous studies of pharmaceutical advertising. Other studies that use market-level data rely on temporal variation in advertising and/or differences in advertising expenditures across markets to identify the effects of advertising (see the references in footnote 1). In contrast to our approach, these studies are more likely to face the reverse causality problem if producers react to underlying variation in the propensity to quit smoking and target their advertising efforts to capture market share. For example, over the calendar year the propensity to quit smoking is probably higher in January due to New Year's resolutions. Producers also advertise smoking cessation products more heavily in January: average advertising expenditures in January are twice as high as in the summer months (Avery et al. 2005a). If producers compete for market share among a fixed stock of New Year's- inspired cessation attempts, it could create a positive association between monthly advertising and cessation rates even if advertising does not causally affect cessation. Relying on variation in advertising expenditures across markets could create a similar bias. For example, according to CDC (2001b) estimates, across major metropolitan areas the rate of adult smoking prevalence varies from a high of 31 percent in Knoxville Tennessee to a low of 13 percent in Orange County California. It would not be surprising for manufacturers of smoking cessation products to compete for market share of potential quitters by targeting heavier-smoking

${ }^{9}$ Rather than an actual coupon, the advertisements typically include a reference to a tollfree telephone number or a website where coupons can be obtained. 
metropolitan areas like Knoxville. Some previous studies use the method of instrumental variables and treat advertising as endogenous, but these studies face the challenge of finding sufficiently powerful IVs that can be excluded from a model like equation (7) and are uncorrelated with the error term. ${ }^{10}$ Given the well-known challenges of IV estimation, we believe our data-driven identification strategy provides a compelling alternative approach.

\section{Results}

Tables 4, 5 and 6 report selected coefficients from our probit models of smoking cessation behaviors. Overall, the results suggest that exposure to smoking cessation advertising does indeed influence the behavior of smokers. When smokers see more advertising, they are more likely to attempt to quit and are more likely to successfully quit (Table 4). In the models reported in Tables 5 and 6, we distinguish whether the quit attempts or successful quits involved the use of a smoking cessation product. We find that exposure to more smoking cessation product advertisements increases quit attempts and successful quits with or without the use of products. In columns 2 and 4 of the Tables we add a quadratic term to allow the probit index to be nonlinear in advertising exposure. In two of the three quit attempt models, we find evidence that the relationship is non-linear. We find no evidence of non-linearities in the models of

${ }^{10}$ Berndt (1991) uses the firm's cost of advertising as his textbook example of an IV that can be excluded as a direct determinant of consumer demand. Advertising costs will be a valid IV, only if they vary over time and/or across markets independently of unobserved determinants in consumer demand. In practice such variation may be hard to find. For example, Iizuka and Jin (2005b) use the average wage in occupations related to the costs of media production as an IV for pharmaceutical advertising. This source of identification will be invalidated, however, if unobserved market-specific shocks drive up wages in media-related occupations and also make the same markets more lucrative places in which to advertise. Our intent here is not to single out for criticism this or any other study that uses IVs, but to stress that the IV approach requires untestable and often controversial assumptions. 
successful quits. We have explored several other specification issues in additional models that are not reported but are available upon request: (i) we find that the effects of advertisements for prescription products were generally similar to the effects of exposure to advertisements for products available over the counter; and (ii) we find that the effects of advertisements across survey waves are generally similar. ${ }^{11}$

Table 7 presents results that illustrate the magnitude of the estimated relationships between advertising exposure and the smoking cessation behaviors. In Table 7 we use our model estimates to predict the probability of the smoking cessation behaviors at different levels of exposure to advertisements for smoking cessation products. To predict each probability, we calculate the underlying index with each person’s actual value of all independent variables except for the smoking cessation product advertising. We then construct five versions of the underlying index with values of smoking cessation advertisements set to $0,5,10,15$, and 20 advertisements. These values span the range of observed magazine advertising for smoking cessation products in our sample during our sample period. For each outcome, we then average the predicted probability across all respondents.

Reading across the top row in Table 7, our model predicts that exposure to an additional five advertisements increases the probability of attempting to quit by almost 1.5 percentage points. The impact of additional advertisements on quit attempts slightly diminishes at higher

\footnotetext{
${ }^{11}$ Estimates from these alternative specifications are relatively imprecise. If firms discover over time that advertisements in certain magazines are more effective, we would expect to find that the estimated impact of the advertisements is higher in later survey waves. This would be problematic for our identification strategy, but we find no evidence it is occurring. We have also examined the pattern of advertisements across magazines over time, and find no obvious signs that advertisers are changing the targeting of their advertisements in response to what they learn over time.
} 
levels of advertising exposure. Interestingly, our results suggest that quit attempts that involve the use of a product are not very responsive to advertisements; quit attempts that do not involve the use of a product are much more responsive. Our model of a successful quit predicts that exposure to an additional five advertisements increase the probability by a little less than $1 / 2$ percentage point. In this case, the impact of additional advertisements on quit attempts slightly increases at higher levels of advertising exposure. Successful quits with and without the use of a product show similar responsiveness to advertising.

The models reported in Tables 4- 6 include a rich set of control variable, but we only report here our findings for exposure to other types of smoking-related advertisements. (An Appendix with complete results is available on request.) The results suggest that exposure to cigarette advertising reduces the probability of attempted and successful quits; this question is explored in detail in Avery et al. (2005b). There is also some evidence that exposure to advertising for other types of tobacco products reduces the probability of a successful quit. We find no evidence that smokers who are exposed to more anti-smoking public service announcements in magazines are more likely to attempt or to successfully quit smoking.

\section{Discussion}

Our empirical results help quantify both the private profits and public health returns to smoking cessation product advertising. A back-of-the-envelope calculation illustrates the magnitude of these returns. If the industry increased its average annual expenditures on magazine advertising by about $\$ 2.6$ million or 10 percent, we calculate that it would expose the 
average consumer to about 3.5 more advertisements each year. ${ }^{12}$ Our empirical models predict that such an increase in advertising would increase cessation attempts by about 1.0 percentage points, from a baseline of 43 percent. In the mid-1990s there were (in round numbers) 50 million smokers, so a 1.0 percentage point increase corresponds to 500,000 new attempts to quit smoking. However, our empirical results also suggest that only about 11,000 of these new quit attempts would involve the use of a smoking cessation product. Assuming the typical user spends about $\$ 300$ on the products, our results suggest that increasing advertising expenditures by $\$ 2.6$ million might increase sales by about $\$ 3.3$ million. ${ }^{13}$ The industry might see some additional future return from stimulating 489,000 attempts where products were not used, to the extent that smokers who fail in their first attempt eventually resort to products in their future attempts. Psychological research suggests that smokers typically make multiple attempts before

${ }^{12}$ Over the period covered in our sample (1996-1999), annual expenditures on magazine advertising averaged about \$26 million (Competitive Media Reports various years). Assuming constant average costs, a 10 percent increase in expenditures corresponds to a 10 percent increase in the number of advertisements. In our sample the average respondent was exposed to 13.5 advertisements in SCADS magazines. Because the SCADS magazines account for somewhere between 30.0 and 57.5 percent of magazine circulation or readership, our measures of advertising exposure probably account for a similar fraction of total advertising exposure. This implies that respondents were exposed to between 23.5 to 45 advertisements in total. We assume the average exposure was 35 advertisements, the approximate mid-point of this range, so a ten percent increase corresponds to 3.5 more advertisements.

${ }^{13}$ Our back-of-the-envelope calculation is too uncertain to draw strong conclusions about the profitability of advertising, but these numbers seem roughly consistent with the first order condition for profit maximization given by equation (3). A key assumption in the calculation is the amount of spending by the typical product user. In 1996, estimates of the maximum cost of three months of the nicotine gum or patch range from $\$ 400$ to $\$ 745$ (Novotny et al 2000, pp. 297-298). The usual recommendation is that the products should be used for up to 10 weeks, so some users may be spending much less than $\$ 400$ - $\$ 745$. Nicotine gum and patches are typically sold in packages containing a 1-week supply or more, so at a minimum product use probably involves expenditures of at least \$35. 
they successfully quit, moving through stages of change from contemplation to action ((Prochaska and DiClemente 1983, DiClemente et al 1991). Advertising might move smokers along in this process.

Our models predict that the public health gains from increasing advertising exposure by 3.5 advertisements would be to increase successful cessation by 0.2 percentage points. With about 50 million current smokers, this implied effect translates into 100,000 additional quits each year. One way to consider the longer-term implications of 100,000 extra quits annually is in terms of steady state smoking prevalence. In the steady state, the rate of smoking prevalence = $\mathrm{i} /(\mathrm{i}+\mathrm{c})$, where $\mathrm{i}$ is the smoking initiation rate and $\mathrm{c}$ is the smoking cessation rate. In the mid1990s, the smoking initiation rate was about 0.01 (1.5 million new smokers/ 150 million non-smoking adults), and the smoking cessation rate was about 0.03 (1.5 million quits/ 50 million smoking adults), yielding a steady state smoking rate of 25 percent. Increasing the smoking cessation rate by 0.2 percentage points implies that the steady state smoking rate falls to 23.8 percent. Although not a large drop, it is more than half of the observed drop over the 1990s, when actual smoking prevalence fell from 25.5 percent in 1990 to 23.3 percent in 2000. Tobacco control efforts have since intensified, especially after the 1998 Master Settlement Agreement with the cigarette industry, and smoking prevalence has fallen further to 20.9 percent (CDC 2005). Private advertising of smoking cessation products may have contributed to some of this drop as well.

Public health advocates have called for more government expenditures on programs to promote smoking cessation. Our analysis and empirical results could be used to argue for subsidies for cessation product advertisements, but it is even simpler to argue for less regulation. 
Avery et al. (2005a) note the irony that in some ways, advertisements of pharmaceutical products for smoking cessation have been more heavily regulated than cigarette advertisements. Food and Drug Administration (FDA) regulations increase the cost of magazine advertisements for prescription products by requiring an extra page of disclosures about side effects. Avery et al. (2005a) estimate if the FDA had allowed all smoking cessation products to be sold over the counter instead of by prescription only, thus escaping this requirement, the number of smoking cessation advertisements would have increased by 80 percent. Looking to the future, the pharmaceutical industry continues to develop new products for smoking cessation; for example, Varenicline, a nicotine agonist, is currently in phase III clinical trials. The Federal Trade Commission has urged the FDA drop its requirement that pharmaceutical print advertisements include detailed drug side-effects listings, in favor of allowing "brief summary" risk warnings (Federal Trade Commission 2004). This regulatory reform could lead to more advertisements for Vanenicline and other new prescription products for smoking cessation. Another potentially very significant regulatory change was the reform of FDA regulations in 1997 which made television advertising of pharmaceuticals much more prevalent. An important direction for future work is to explore the impact of televison advertisements on smoking cessation.

The spillover effects we identify have broader implications for the economics of advertising. Many theoretical and empirical studies of the economics of advertising focus on strategic interactions between firms selling competing products in a market. In our case study, advertisements for smoking cessation products generate spillover benefits because smokers can also quit smoking by cold turkey, do-it-yourself methods that do not involve market purchases. Non-market household production is central to the economics of health behaviors (Grossman 
1972, 2000), and advertisements for other pharmaceutical products may generate spillover effects for health behaviors other than smoking cessation. For example, statin drugs to reduce high blood cholesterol are heavily advertised. Because the Clinical Practice Guidelines for cholesterol control recommend dietary changes, exercise, and weight loss before beginning drug therapy (National Institutes of Health 2001), DTC advertisements for statins could lead to these healthier behaviors. In fact, in a survey of consumers who discussed an advertised drug during a physician visit, 52 percent report that their physician suggested a health behavior change, while only 43 percent report receiving a prescription for the advertised drug (Weissman et al. 2003). Because consumers may also substitute advertised products for health behavior changes, the net public health impact of DTC advertising is ambiguous, although presumably consumer welfare increases. Even more generally than DTC advertising and health behaviors, advertising of a wide range of consumer products may have important and under-studied spillover effects on various non-market behaviors. 


\section{References}

Audit Bureau of Circulations (2003). Magazine trend report. Schaumburg, IL.

Avery, Rosemary, Kenkel, Donald S., Lillard, Dean R., and Mathios, Alan D. (2005a)

"Regulating Advertisements: The Case of Smoking Cessation Products." Working Paper, Department of Policy Analysis and Management, Cornell University.

. (2005b) “Cigarette Advertisements and Smoking Cessation.” Presentation given at the International Health Economics Association Conference, Barcelona, Spain, July 2005.

Bagwell, Kyle (2005). The Economics of Advertising. Online Paper, Department of Economics, Columbia University, August 2005.

Bradford, W. David and Andrew N. Kleit (2006). “Direct to Consumer Advertising.” In Andrew Jones, editor, Elgar Companion to Health Economics (forthcoming).

Becker, Gary S. and Kevin M. Murphy (1988). "A Theory of Rational Addiction," Journal of Political Economy 96 (4): 675-700.

Berndt, Ernst R. (1991). The Practice of Econometrics: Classic and Contemporary. Addison-Wesley

Berndt, Ernst R., Linda Bui, David R. Reiley, and Glen L. Urban (1995). “Information, Marketing, and Pricing in the U.S. Antiulcer Drug Market.” American Economic Review Papers and Proceedings 85 (2): 100 - 105.

Burton, SL, KE Kemper, TA Baxter, S Shiffman, J Gitchell, and C Currence. (1997). “Impact of Promotion of the Great American Smokeout and Availability of Over-the-Counter Nicotine Medications, 1996.” Morbidity and Mortality Weekly Report 46 (37): 867 869.

Calfee, John E., Winston, Clifford, and Stempski, Randolph. (2002). "Direct-to-Consumer Advertising and the Demand for Cholesterol-Reducing Drugs." The Journal of Law and Economics, 45: 673-690 .

Centers for Disease Control and Prevention [CDC]. (1999). Best Practices for Comprehensive Tobacco Control Programs - August 1999. Atlanta, Georgia: U.S. Department of Health and Human Services, Centers for Disease Control and Prevention, National Center for Chronic Disease Prevention and Health Promotion, Office on Smoking and Health.

Centers for Disease Control and Prevention [CDC]. (2001a). Investment in Tobacco Control: State Highlights 2001. U.S. Department of Health and Human Services. 
Centers for Disease Control and Prevention [CDC]. (2001b). “Cigarette Smoking in 99 Metropolitan Areas.” Morbidity and Mortality Weekly Reports 50 (49): 1107-1111.

Centers for Disease Control and Prevention [CDC]. (2005) "Smoking Prevalence Among U.S. Adults.” Http://www.cdc.gov/tobacco/research_data/adults_prev/prevali.htm. Accessed December 22, 2005.

Competitive Media Reports (various years). "AdSpender." www.tnsmi-mi.com/

DiClemente, C.C., Proschaska, J.O., Fairhurst, S.K., Velicer, W.F., Velasquez, M.M., and Rossi, J.S. (1991). "The Process of Smoking Cessation: An Analysis of Precontemplation, Contemplation, and Preparation Stages of Change." Journal of Consulting and Clinical Psychology 59 (2): 295-304.

Dorfman, R. and Steiner, P.O. (1954). “Optimal Advertising and Optimal Quality” American Economic Review 44: 826-836.

Federal Trade Commission (2004). Comments of the Staff of the Bureau of Consumer Protection, the Bureau of Economics, and the Office of Policy Planning. "Before the Department of Health and Human Services Food and Drug Administration, In the Matter of Request for Comments on Agency Draft Guidance Documents Regarding ConsumerDirected Promotion.” Docket No. 2004D-0042.

Fiore, Michael C., William C. Bailey, Stuart J. Cohen, et al. (2000). Treating Tobacco Use and Dependence. Clinical Practice Guideline. Rockville, MD: U.S. Department of Health and Human Services. Public Health Service. June 2000.

Fiore, Michael C., Robert T. Croyle, Susan J. Curry, et al. (2004). “Preventing 3 Million Premature Deaths and Helping 5 Million Smokers Quit: A National Plan for Tobacco Cessation.” American Journal of Public Health 94 (2): 205-210.

Grossman, Michael (1972). “On the Concept of Health Capital and the Demand for Health.” Journal of Political Economy 80 (2) 223-255.

Grossman, Michael (2000). “The Human Capital Model,”in the Handbook of Health Economics, A.J. Cuyler and J.P. Newhouse, editors. North-Holland, pp. 349-408.

Ippolito, Pauline M. and Alan Mathios (1990) "Information, Advertising and Health Choices: A Study of the Cereal Market.” RAND Journal of Economics 21 (3):459-480.

Ippolito, P. and Mathios, A., (1995) "Information and Advertising: The Case of Fat Consumption in the United States," American Economic Review: Papers and Proceedings, 85 (2) May. 
Iizuka, Toshiaki, and Jin, Ginger Z. (2005a). “The Effect of Prescription Drug Advertising on Doctor Visits” Journal of Economics \& Management Strategy14: 701 (September).

Iizuka, Toshiaki, and Jin, Ginger Z. (2005b). “Drug Advertising and Health Habits.” NBER Working Paper 11770.

Jones, Andrew M. (1999). “Adjustment Costs, Withdrawal Effects, and Cigarette Addiction.” Journal of Health Economics 18 (1): 125-137.

Ling, Davina C., Ernst R. Berndt, and Margaret K. Kyle (2002). “Deregulating Direct-toConsumer Marketing of Prescription Drugs: Effects on Prescription and Over-theCounter Product Sales.” Journal of Law and Economics, XL: 691-723.

Manning, Willard, Emmett Keeler, Elizabeth Sloss, Jeffery Wasserman and Joseph P. Newhouse, (1991) The Costs of Poor Health Habits, Harvard University Press, Cambridge, Mass.

Marketdata Enterprises (2000). Smoking Cessation Products \& Services: A Market Analysis. Tampa, Florida: Marketdata Enterprises, Inc.

Market Research.com. (2005). “Market Trends: Smoking Cessation Products” http://www.marketresearch.com/product/display.asp?ProductID=1073655\&g=1

Mendez, David and Kenneth E. Warner (2000). "Smoking Prevalence in 2010: Why the Healthy People Goal is Unattainable.” American Journal of Public Health 90: 401-403. (2004). “Adult Cigarette Smoking Prevalence: Declining as Expected (Not as Desired).” American Journal of Public Health 94: 251-252.

National Consumer Survey [NCS] (2005). http://www.directionsmag.com/companies/Simmons_Market_Research_Bureau/

National Institutes of Health (2001). Detection, Evaluation, and Treatment of High Blood Cholesterol in Adults (Adult Treatment Panel III). Third Report of the National Cholesterol Education Program Expert Panel. National Heart, Lung, and Blood Institute, National Institutes of Health. NIH Publication No. 01-3670.

Novotny, T.E., Cohen, J.C., Yureliki, A., Sweanor, D., and de Beyer, J. (2000). “Smoking cessation and nicotine replacement therapies.” in P. Jha and F. Chaloupka, editors. Tobacco Control in Developing Countries. Oxford and New York: Oxford University Press, pp. 287-307. 
Patrick, D.L., Cheadle, A., Thompson, D.C., Diehr, P., Koepsell, T., and Kinne, S. (1994). "The Validity of Self-Reported Smoking: A Review and Meta-Analysis." American Journal of Public Health (July): 1086-1093.

Plassmann, V., Kenkel, D., Lillard, D.R., and Mathios, A. (2005). "Smoking Cessation: An Analysis of Quit Methods” Working Paper, Department of Policy Analysis and Management, Cornell University.

Prochaska J O and C C DiClemente (1983). "Stages and Process of Self-change of Smoking: Toward an Integrative Model of Change.” Journal of Consulting and Clinical Psychology 51 (3): 390-395.

Rosenthal, Meredith B., Ernst R. Berndt, Julie M. Donohue, Richard G. Frank, and Arnold M. Epstein (2002). "Promotion of Prescription Drugs to Consumers," New England Journal of Medicine 346 (7): 498 - 505.

Rosenthal, Meredith B., Ernst R. Berndt, Julie M. Donohue, Arnold M. Epstein, and Richard G. Frank (2003). "Demand Effects of Recent Changes in Prescription Drug Promotion." In Frontiers in Health Policy Research, Vol. 6, edited by Alan M. Garber and David M. Cutler. Cambridge, Mass.: MIT Press (for National Bureau of Economic Research).

Schmalensee, R. (1972). The Economics of Advertising Amsterdam: North Holland.

Sloan, Frank A., Jan Ostermann, Gabriel Picone, Christopher Conover, and Donald H. Taylor, Jr. (2004). The Price of Smoking. Cambridge Massachusetts: The MIT Press.

Suranovic, Steven M., Robert S. Goldfarb and Thomas C. Leonard (1999). “An Economic Theory of Cigarette Addiction.” Journal of Health Economics 18(1):1-29.

Tauras, John A., Frank J. Chaloupka, and Sherry Emery (2005). “The Impact of Advertising on Nicotine Replacement Therapy Demand.” Social Science \& Medicine 60: 2351-2358.

U.S. Department of Health and Human Services [USDHHS] (2000). Healthy People 2010. $2^{\text {nd }}$ Edition. With Understanding and Improving Health and Objectives for Improving Health. 2 vols. Washington, DC: U.S. Government Printing Office.

Viscusi, Kip W. (1995). “Cigarette Taxation and the Social Consequences of Smoking.” In James Porteba (ed.), Tax Policy and the Economy. Cambridge, Mass: The MIT Press.

Weissman, Joel S., David Blumenthal, Alvin J. Silk, Kinga Zapert, Michael Newman, and Robert Leitman (2003). “Consumers' Reports on the Health Effects of Direct-ToConsumer Drug Advertising.” Health Affairs Web Exclusive W3-82 - W3-95. 
Wosinska, Marta (2003). “Just What the Patient Ordered? Direct-to-Consumer Advertising and the Demand for Pharmaceutical Products.” Harvard Business School Working Paper No. 03-058.

Wosinska, Marta (2005). "Direct-to-Consumer Advertising and Drug Therapy Compliance." Journal of Marketing Research (August 2005). 


\begin{tabular}{|c|c|c|}
\hline \multicolumn{3}{|c|}{ Table1 Descriptive statistics for selected variables } \\
\hline Variable & $\begin{array}{c}\text { Mean } \\
\text { (Std. Dev.) }\end{array}$ & Variable definition \\
\hline Attempted to quit* & 0.43 & $=1$ if tried to quit in past 12 months, 0 othervise \\
\hline Attempted to quit and used product* & 0.02 & $\begin{array}{l}=1 \text { if tried to quit in past } 12 \text { months and used product, } 0 \\
\text { othervise }\end{array}$ \\
\hline Successfully quit* & 0.09 & $=1$ if tried to quit and non smoker, 0 otherwise \\
\hline Successfully quit and used product* & 0.10 & $\begin{array}{l}=1 \text { if tried to quit, used product, and non smoker, } 0 \\
\text { otherwise }\end{array}$ \\
\hline Attempted to quit and did not use product* & 0.32 & $\begin{array}{l}=1 \text { if tried to quit in past } 12 \text { months and did not use } \\
\text { product, } 0 \text { otherwise }\end{array}$ \\
\hline Successfully quit and did not use product* & 0.07 & $\begin{array}{l}=1 \text { if tried to quit, did not use product, and non smoker, } 0 \\
\text { otherwise }\end{array}$ \\
\hline Advertising exposure & & $\begin{array}{l}\text { Advertisements (in SCADS magazines read over past } \\
12 \text { months) for: }\end{array}$ \\
\hline Smoking cessation products & $\begin{array}{c}13.49 \\
(1288)\end{array}$ & $\begin{array}{l}\text {-Habitrol, Nicoderm patch, Ncorette Gum, Nicotrol } \\
\text { (Inhaler, patch), Prostep patch, Zyban }\end{array}$ \\
\hline Gigarettes & $\begin{array}{c}144.88 \\
(138.12)\end{array}$ & -all cigarettes \\
\hline Other tobacco products & $\begin{array}{c}4.57 \\
(9.13) \\
\end{array}$ & $\begin{array}{l}\text {-snuff, cheving tobacco, rolling tobacco, cigars, and } \\
\text { cigarillos }\end{array}$ \\
\hline Public service announcements & 0.77 & $\begin{array}{l}\text {-public senice announcements aimed at getting smokers } \\
\text { to quit }\end{array}$ \\
\hline \multicolumn{3}{|l|}{ Media exposure } \\
\hline Magazine issues read in year & $\begin{array}{r}144.25 \\
(137.56) \\
\end{array}$ & Number of magazine issues read in previous 12 months \\
\hline Read no magazines* & 0.04 & $\begin{array}{l}=1 \text { if read no magazines in previous } 12 \text { months, } 0 \\
\text { otherwise }\end{array}$ \\
\hline No cigarette advertising magazine* & 0.58 & $\begin{array}{l}=1 \text { if read at least one issue of Good Housekeeping, } \\
\text { Mbdern Maturity, National Geographic, Seventeen, or } \\
\text { Reader's Digest }\end{array}$ \\
\hline TVhours & $\begin{array}{r}23.15 \\
(2273) \\
\end{array}$ & Hours watch television in average week \\
\hline Watchno TV in average week* & 0.16 & $=1$ if watch no television in average week \\
\hline Radiohours & $\begin{array}{c}4.14 \\
(6.61)\end{array}$ & Hours listen to rado in average week \\
\hline Listen to no radio in average week* & 0.26 & $=1$ if listen to no radio in average week \\
\hline \multicolumn{3}{|c|}{$\begin{array}{l}\text { *Indicator variables - figure denotes percent of sample. N=36,097 Source: Miliple waves of NCS surveys and } \\
\text { SCADS archive. }\end{array}$} \\
\hline
\end{tabular}


Table 2. Fraction of smokers who attempted to quit and successfully quit, by quartile of distribution of smoking cessation product advertising exposure

\begin{tabular}{|l|c|c|}
\hline & & \\
\hline Quartile & Attempted & Succeeded \\
\hline Q1 (0 to 3.1 advertisements) & 0.396 & 0.095 \\
\hline Q2 (3.1 to 10.3 advertisements) & 0.413 & 0.091 \\
\hline Q3 (10.3 to 20.0 advertisements) & 0.433 & 0.090 \\
\hline Q4 (20 or more advertisements) & 0.464 & 0.098 \\
\hline
\end{tabular}

Source: Simmons NCS surveys and SCADS archive. 


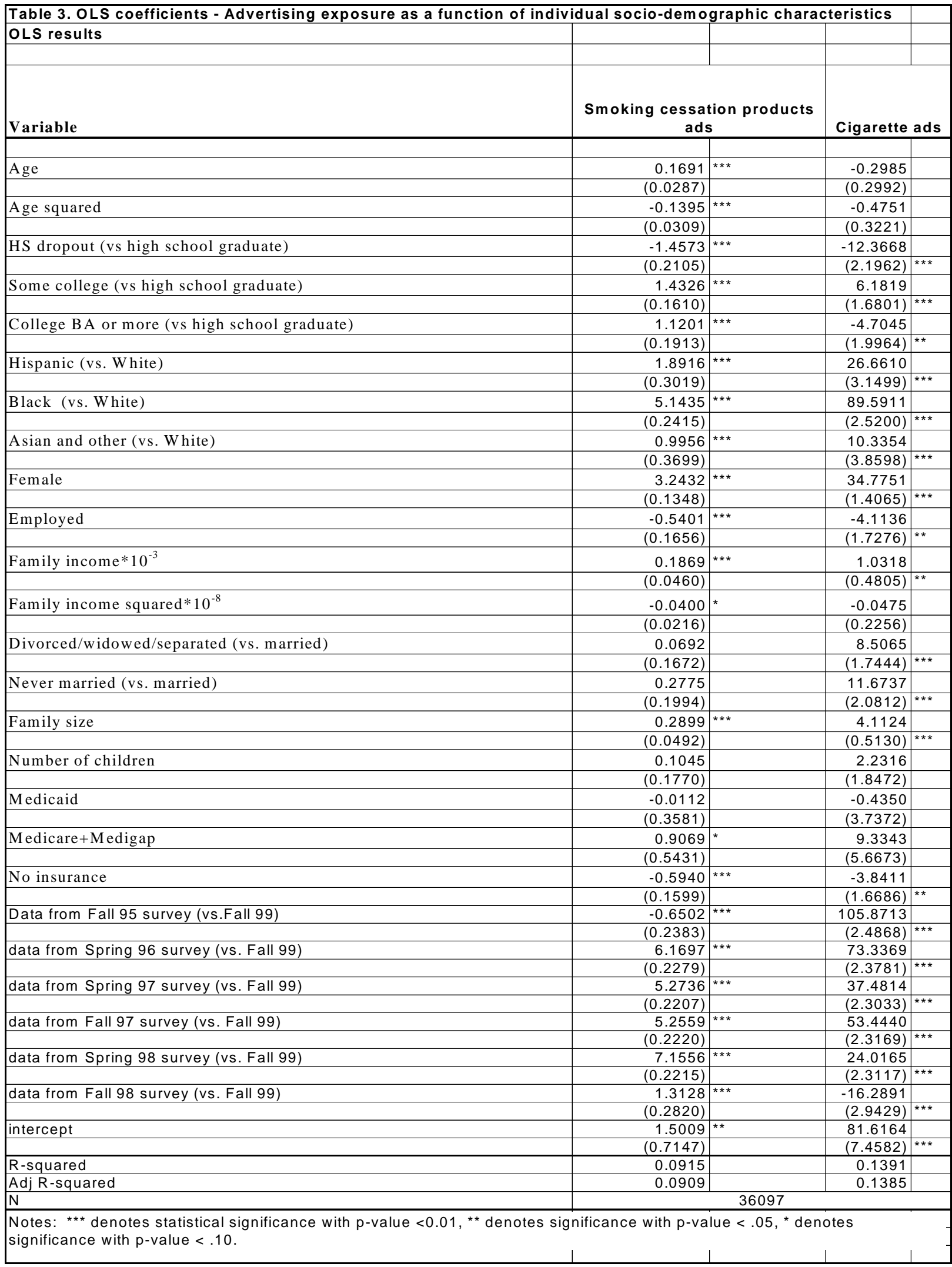




\begin{tabular}{|c|c|c|c|c|}
\hline \multicolumn{5}{|c|}{ Table 4. Selected probit coefficients - Quit attempt and successful quit } \\
\hline & & & & \\
\hline & \multicolumn{2}{|c|}{ Quit Attempt } & \multicolumn{2}{|c|}{ Successful Quit } \\
\hline Variable & \begin{tabular}{l|l|}
1 & \\
\end{tabular} & 2 & \begin{tabular}{l|l}
1 & \\
\end{tabular} & 2 \\
\hline \multirow[t]{2}{*}{ Smoking cessation product advertisements } & $0.0045^{\star \star \star ~}$ & 0.0086 *ᄎ* & $0.0053^{\star \star \star}$ & 0.0033 \\
\hline & $(0.0012)$ & $(0.0021)$ & $(0.0016)$ & $(0.0029)$ \\
\hline \multirow[t]{2}{*}{ Smoking cessation product advertising ${ }^{2} * 10^{-2}$} & & -0.0075 ** & & 0.0037 \\
\hline & & $(0.0032)$ & & $(0.0044)$ \\
\hline \multicolumn{5}{|l|}{ Other advertising exposure: } \\
\hline \multirow[t]{2}{*}{ Gigarette advertisements*10 $0^{-2}$} & $-0.0397 * \star \star$ & $-0.0404 * \star \star$ & $-0.0506 * \star *$ & $-0.0505 * \star \star$ \\
\hline & $(0.0125)$ & $(0.0126)$ & $(0.0178)$ & $(0.0178)$ \\
\hline \multirow[t]{2}{*}{ Advertisements for other tobacco products } & -0.0012 & -0.0009 & -0.0042 & $-0.0043 * * \star$ \\
\hline & $(0.0011)$ & $(0.0011)$ & $(0.0016)$ & $(0.0016)$ \\
\hline \multirow[t]{2}{*}{ Public service announcements } & -0.0096 & -0.0100 & -0.0100 & -0.0097 \\
\hline & $(0.0071)$ & $(0.0071)$ & $(0.0101)$ & $(0.0101)$ \\
\hline LRchiz(k) & 867.17 & 872.6 & 660.43 & 661.11 \\
\hline $\mathrm{k}$ & 148 & 149 & 148 & 149 \\
\hline Prob > chi2 & 0 & 0 & 0 & 0 \\
\hline Log likelihood & -24196.6 & -24193.9 & -10886.8 & -10886.4 \\
\hline Pseudo R2 & 0.0176 & 0.0177 & 0.0294 & 0.0295 \\
\hline & \multirow{2}{*}{\multicolumn{2}{|c|}{15399}} & & \\
\hline Tried to quit & & & & \\
\hline Didn't try to quit & \multicolumn{2}{|c|}{20698} & & \\
\hline Total N & \multicolumn{2}{|c|}{36097} & & \\
\hline Successfully quit & & & 33 & 378 \\
\hline Didn't try to quit or tried and failed & & & 32 & 719 \\
\hline Total N & & & 36 & 097 \\
\hline \multicolumn{5}{|c|}{$\begin{array}{l}\text { Notes: *k denotes statistical significance with p-value }<0.01 \text {, }{ }^{*} \text { denotes significance with p-value }<.05 \text {, * } \\
\text { denotes significance with p-value <.10. Other controls include age, age squared, education (three categories), } \\
\text { race (three categories), sex, employment status, family income, family income squared, marital status (two } \\
\text { categories), family size, presence of children in household, indicators for survey wave (season and period), } \\
\text { indicator for SCADS magazines that accept no cigarette advertising, total issues of magazines read, indicator for } \\
\text { people who read no magazines, TV hours watched in average week, Radio hours listened in average week, } \\
\text { watch no TV, listen to no radio, indicators for four categories of SCADS magazines (womens', young womens', } \\
\text { African American, men's, general interest), and indicator for individual magazines other than SCADS. }\end{array}$} \\
\hline
\end{tabular}




\begin{tabular}{|c|c|c|c|c|}
\hline \multicolumn{5}{|c|}{ Table 5. Selected probit coefficients - Quit attempt and successful quit using smoling cessation product } \\
\hline & & & & \\
\hline \multirow[b]{2}{*}{ Vaniable } & \multicolumn{2}{|c|}{ Quit Attempt } & \multicolumn{2}{|c|}{ Successful Qiit } \\
\hline & \begin{tabular}{l|l}
1 & \\
\end{tabular} & 2 & \begin{tabular}{l|l}
1 & \\
\end{tabular} & 2 \\
\hline \multirow[t]{2}{*}{ Smoking cessation product advertisements } & $0.0027^{\star}$ & 0.0002 & $0.0064^{\text {** }}$ & 0.0030 \\
\hline & $(0.0016)$ & $(0.0029)$ & $(0.0028)$ & $(0.0050)$ \\
\hline \multirow[t]{2}{*}{ Smoking cessation product advertising ${ }^{2} * 10^{-2}$} & & 0.0044 & & 0.0062 \\
\hline & & $(0.0043)$ & & $(0.0075)$ \\
\hline \multicolumn{5}{|l|}{ Other advertising exposure: } \\
\hline \multirow[t]{2}{*}{ Ggarette advertisements $* 10^{-2}$} & $-0.03977^{\star \star}$ & $-0.03977^{\star \star}$ & 0.0095 & 0.0096 \\
\hline & (0.0176) & $(0.0176)$ & (0.0314) & (0.0314) \\
\hline \multirow[t]{2}{*}{ Advertisements for other tobacco products } & -0.0006 & -0.0008 & -0.0049 * & $-0.0051 *$ \\
\hline & $(0.0016)$ & (0.0016) & $(0.0029)$ & $(0.0029)$ \\
\hline \multirow[t]{2}{*}{ Public service announcements } & -0.0067 & -0.0063 & $-0.1357 * * *$ & -0.1338 * \\
\hline & $(0.0102)$ & $(0.0102)$ & $(0.0221)$ & $(0.0221)$ \\
\hline LRchiz(k) & 940.74 & 941.82 & 429.53 & 430.19 \\
\hline $\mathrm{k}$ & 148 & 149 & 148 & 149 \\
\hline Prob > chi2 & 0 & 0 & 0 & 0 \\
\hline Log likelihood & -11404.8 & -11404.261 & -3183.3534 & -3183.0206 \\
\hline Pseudo R2 & 0.0396 & 0.0397 & 0.0632 & 0.0633 \\
\hline Tried to quit with smoking cessation product & \multicolumn{2}{|c|}{3674} & & \\
\hline All others & \multicolumn{2}{|c|}{32423} & & \\
\hline Total N & \multicolumn{2}{|c|}{36097} & & \\
\hline Successfully quit with smoking cessation product & & & & 36 \\
\hline All others & & & & 111 \\
\hline Total N & & & & 99 \\
\hline \multicolumn{5}{|c|}{ 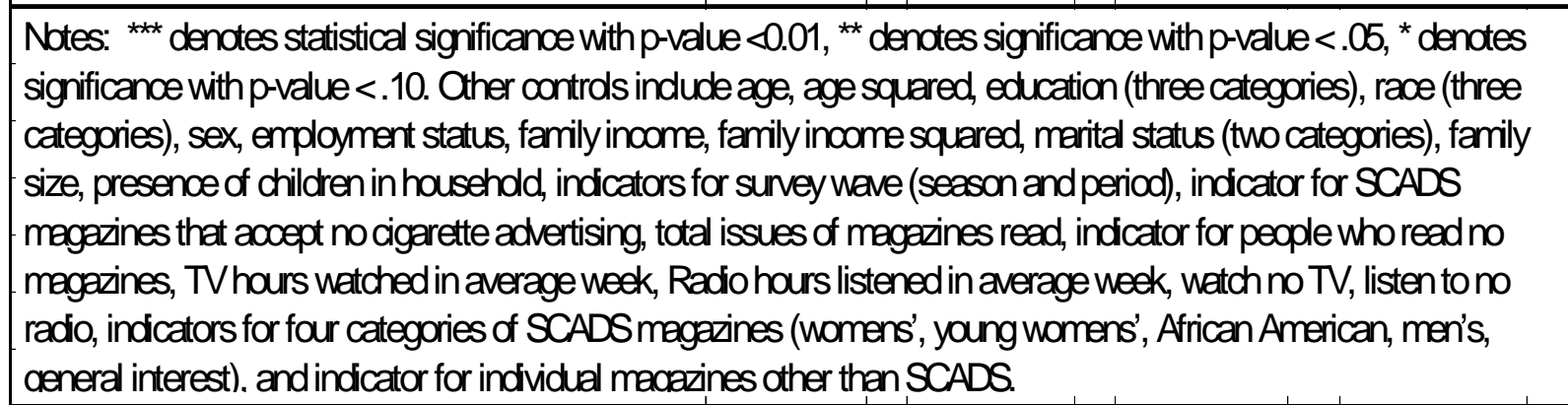 } \\
\hline
\end{tabular}




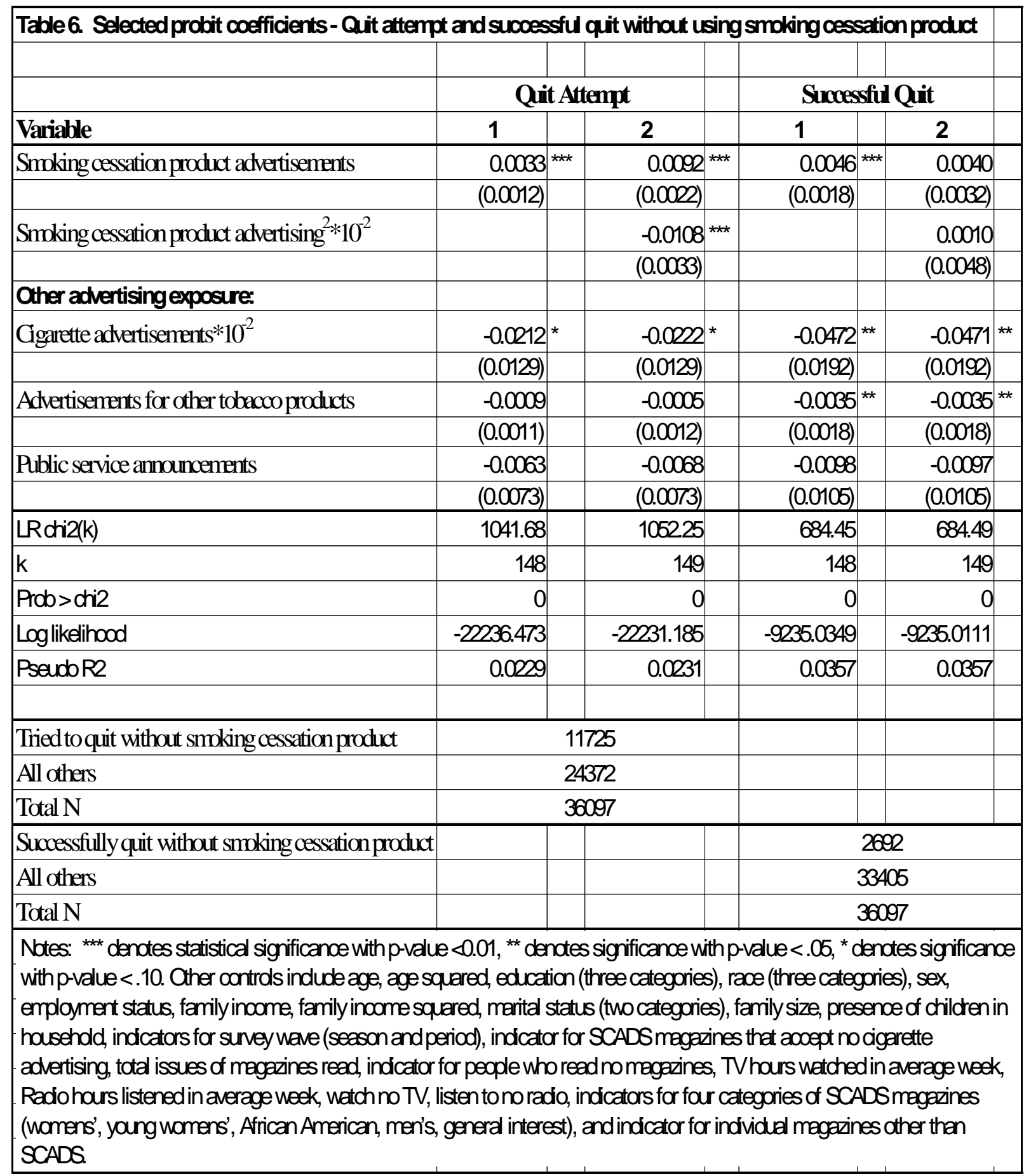




\begin{tabular}{|c|c|c|c|c|c|}
\hline & & & & & \\
\hline & \multicolumn{5}{|c|}{ Advertisements seen in past year } \\
\hline & 0 & 5 & 10 & 15 & 20 \\
\hline Probability of attempted quit & 0.392 & 0.408 & 0.422 & 0.435 & 0.447 \\
\hline Probability of attempted quit using product & 0.099 & 0.099 & 0.100 & 0.101 & 0.102 \\
\hline Probability of attempted quit without using product & 0.295 & 0.310 & 0.323 & 0.334 & 0.344 \\
\hline Probability of successful quit & 0.085 & 0.088 & 0.091 & 0.094 & 0.098 \\
\hline Probability of successful quit using product & 0.017 & 0.017 & 0.018 & 0.019 & 0.020 \\
\hline Probability of successful quit without using product & 0.067 & 0.070 & 0.073 & 0.075 & 0.079 \\
\hline
\end{tabular}




\begin{tabular}{|c|c|c|}
\hline \multicolumn{3}{|l|}{ Appendix Table 1 Descriptive statistics } \\
\hline Variable & Mean & Std. Deviation \\
\hline Attempted to quit* & 42.66 & \\
\hline Successfully quit* & 9.36 & \\
\hline \multicolumn{3}{|l|}{ Advertising exposure } \\
\hline Smoking cessation products & 13.49 & 12.88 \\
\hline Cigarettes & 144.88 & 138.12 \\
\hline Other tobacco products & 4.57 & 9.13 \\
\hline Anti-smoking public service announcements & 0.77 & 1.49 \\
\hline \multicolumn{3}{|l|}{ Type of health insurance held } \\
\hline Private* & 70.23 & \\
\hline Medicaid* & 3.74 & \\
\hline Medicaid+Medigap* & 1.55 & \\
\hline No insurance* & 24.49 & \\
\hline \multicolumn{3}{|l|}{ Media exposure } \\
\hline Magazine issues read in year & 144.25 & 137.56 \\
\hline Read no magazines* & 4.32 & \\
\hline Reader of 1+ magazines that accept no cigarette advertising* & 57.8 & \\
\hline Average weekly hours of television viewing & 23.15 & 22.73 \\
\hline Watch no TV in average week* & 15.8 & \\
\hline Average weekly hours of radio listening & 4.14 & 6.61 \\
\hline Listen to no radio in average week* & 26.33 & \\
\hline \multicolumn{3}{|l|}{ Other control variables } \\
\hline Age & 43.04 & 14.39 \\
\hline Family income & 51311.43 & 41612.85 \\
\hline Family size & 3.01 & 1.74 \\
\hline Children in household* & 59.31 & \\
\hline Education less than high school* & 13.82 & \\
\hline Education high school diploma* & 33.06 & \\
\hline Education some college* & 33.21 & \\
\hline Education B.A. and higher* & 19.91 & \\
\hline White* & 83.56 & \\
\hline Hispanic* & 4.98 & \\
\hline Black* & 8.24 & \\
\hline Asian and other* & 3.21 & \\
\hline Female* & 52.92 & \\
\hline Employed* & 71.31 & \\
\hline Married* & 51.35 & \\
\hline Divorced/widowed/separated* & 26.87 & \\
\hline Never married* & 21.78 & \\
\hline \multicolumn{3}{|l|}{ Survey wave } \\
\hline Fall 1995* & 11.71 & \\
\hline Spring 1996* & 14.82 & \\
\hline Spring 1997* & 15.08 & \\
\hline
\end{tabular}




\begin{tabular}{|l|r|r|}
\hline Appendix Table 1 continued & \\
\hline Variable & Mean & Std. Deviation \\
\hline Fall 1997* & 14.65 & \\
\hline Spring 1998* & 14.67 & \\
\hline Fall 1998* & 6.91 & \\
\hline Fall 1999* & 22.15 & \\
\hline $\mathrm{N}=36,097$ & \\
*Indicator variables - figure denotes percent of sample & \\
Source: Multiple waves of NCS surveys. See Table 2 for variable definitions. & \\
\hline
\end{tabular}




\section{DATA APPENDIX}

\section{The SCADS Archive}

The SCADS archive is a collection of all print advertisements for smoking cessation products, tobacco products, and smoking-related public service announcements that appeared between January 1985 and May 2002 in 26 consumer magazines. The magazine set includes: Better Homes \& Gardens, Black Enterprise, Business Week, Cosmopolitan, Ebony, Essence, Family Circle, Glamour, Good Housekeeping, Jet, McCall's (name changed to Rosie's on January 1, 2001), Modern Maturity, Money, National Geographic, Newsweek, People, Playboy, Readers Digest, Rolling Stone, Seventeen, Sports Illustrated, Time, TV Guide, U.S. News \&World Report, Vogue, and Women's Day. SCADS also includes advertisements from two medical journals: the Journal of the American Medical Association and the New England Journal of Medicine. Because the NCS does not ask whether respondents read these journals, we do not include them in our analysis.

We selected these magazines to represent magazines most frequently read by individuals with particular demographic characteristics. We defined 22 groups by race (3 groups), education (5 groups), income (5 groups), age (5 groups), gender (2 groups), and smoking status (2 groups). Using data on magazine reading from the 1998 NCS we chose the ten magazines most frequently read by members of each group. Although we defined 22 groups, members of each group often read the same magazines. Consequently, instead of 220 magazines, the final set includes the above 26 magazines. We were unable to use three magazines because we could not locate all issues in our sample period. In those three cases we substituted the next most widely read magazine for the group in question. Using magazine circulation data from three independent sources, we estimate that the 26 magazines in SCADS account for between 30.0 and 57.5 percent of magazines circulating in the US. The lower figure is based on total circulation across 580 magazines reported in Audit Bureau of Circulation's (2003) Magazine Trend Report. The higher figure is estimated from readership data for the 172 magazines included in the NCS. The SCADS magazines represents 5\% of the 580 magazines in the Magazine Trend Report data but account for 30.0 percent of circulation.

\section{The Simmons National Consumer Survey (NCS)}

The NCS is a repeated cross-sectional survey. The sample for each wave is independently drawn. The NCS employs a multi-stage stratified probability sample. The final sample represents a representative probability sample of all adults living in households in the U.S. (excluding Hawaii and Alaska). In order to minimize respondent fatigue the data are collected in several phases. In Phase 1 respondents are interviewed (face-to-face). In Phase 1 interviewers collect demographic data and data on the magazines respondents read. To collect this information interviewers present respondents with a deck of cards on each of which is printed the logo of one of the 182 magazines in the Simmons sample. If a respondent reports that he has read any portion of a magazine he is asked a set of questions about readership, including whether he reads the whole magazine. During the second part of Phase 1 respondents 
report, by filling out a questionnaire, whether they purchase and use specific products, including smoking cessation products.

Survey response rates in the NCS are generally high (approximately 70 percent) and compare well with other widely-used surveys in health economics and health services research. For example: in the 2002 Behavioral Risk Factor Surveillance Survey the median response rate across states was 58 percent (range: 42 percent to 83 percent); for the 2002 National Health Interview Survey (NHIS) the total household response rate was approximately 90 percent and the final response rate for the Adult Sample Person was 74 percent (CDC 2003, 2004).

The rates of smoking behaviors in the NCS are very similar to rates estimated from other national data sets. In the NCS, approximately 26 percent of the 1995 sample smoke and 24 percent of the 1998 sample smoke. By comparison, from the NHIS, the CDC $(1997,2003)$ estimates that the prevalence of smoking among adults was 25 percent in 1995 and 24 percent in 1998. In the pooled waves of the 1995-1999 NCS, about 43 percent of smokers reported that they attempted to quit during the past year. By comparison, in the 1995 NHIS, 46 percent of current daily smokers had stopped smoking for at least one day during the past year because they were trying to quit; in the 1998 and 2000 NHIS the quit attempt rates were 39 percent and 49 percent, respectively. (The slight differences between the NCS and the 1995 and 2000 NHIS estimates of the prevalence of quit attempts are probably due to differences in the wording of the survey questions used to define a quit attempt; it is not clear why the rate of quit attempts is lower in the 1998 NHIS.) In the pooled waves of the 1995-1998 NCS, of those who attempted to quit, 22 percent were not smoking at the time of the survey. In the 2000 NHIS, 22 percent of those who attempted to quit were successful. Of smokers who attempted to quit: 21.9 percent of NCS respondents using a smoking cessation product, compared to 20.1 percent in the NHIS. We have also completed a descriptive study that uses the 1995-1999 NCS data and the 2000 NHIS to explore socio-economic differences in quit attempts and in quit methods used (Plassman et al. 2005). The NCS and NHIS samples are very similar in terms of socio-economic characteristics such as age, family income, education, ethnicity, and health insurance status.

\section{Additional References}

Centers for Disease Control and Prevention (1997). “Cigarette Smoking Among Adults - United States, 1995.” Morbidity and Mortality Weekly Report 46 (51): 1217-1220.

Centers for Disease Control and Prevention (2003). “Cigarette Smoking Among Adults - United States, 1998.” Morbidity and Mortality Weekly Report 49 (39): 881-884.

Centers for Disease Control and Prevention (2004). "State-Specific Prevalence of Current Cigarette Smoking Among Adults - United States, 2002.” Morbidity and Mortality Weekly Report 52 (53): 1277-1280. 